\title{
Exposure to air pollution and cognitive impairment risk: a meta-analysis of longitudinal cohort studies with dose-response analysis
}

\author{
Xiaohui Yu, Liwen Zheng, \\ Wenjie Jiang, Dongfeng \\ Zhang
}

Department of Epidemiology and Health Statistics, the School of Public Health of Qingdao University, People's Republic of China

\begin{abstract}
Background We conducted a meta-analysis to explore the relationship between exposure to air pollution and the risk of cognitive impairment of longitudinal cohort studies.

Methods PubMed, Web of Science and Wan Fang databases were searched for relevant articles of longitudinal cohort studies published between January 1950 and September 2019. The pooled relative ratio (RR) and 95\% confidence interval (CI) were calculated using the random effect model.

Results Ten articles involving 519247 cases among 12523553 participants were included in this meta-analysis. The pooled RR of cognitive impairment per $5 \mu \mathrm{g} / \mathrm{m}^{3}$ increments in exposure to particulate matter $\leq 2.5 \mu \mathrm{m}\left(\mathrm{PM}_{2.5}\right)$ was 1.08 (95\% CI $\left.=1.03,1.13 ; I^{2}=82.2 \% ; P_{\text {heterogeneity }}<0.001\right)$. No association was found between nitrogen dioxide/nitrogen oxide $\left(\mathrm{NO}_{2} / \mathrm{NO}_{\mathrm{x}}\right)$ and ozone $\left(\mathrm{O}_{3}\right)$ and cognitive impairment. For $\mathrm{PM}_{2.5}$ exposure, in subgroup analysis, the above-mentioned significant positive association was found among studies conducted in population $\left(\mathrm{RR}_{\text {per } 5 \mu \mathrm{g} / \mathrm{m}^{3}}=1.05 ; 95 \% \mathrm{CI}=1.01,1.09 ; I^{2}=57.4 \%\right.$;

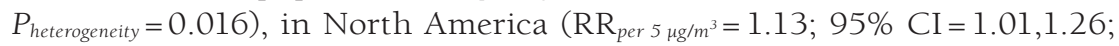
$\left.I^{2}=86.7 \% ; P_{\text {heterogeneity }}<0.001\right)$ and with follow-up duration $>10$ years $\left(\mathrm{RR}_{\text {per } 5 \mu \mathrm{g} / \mathrm{m}^{3}}=1.10 ; 95 \% \mathrm{CI}=1.03,1.17 ; I^{2}=86.3 \% ; P_{\text {heterogeneity }}<0.001\right)$.
\end{abstract}

Conclusions This meta-analysis suggests that exposure to $\mathrm{PM}_{2.5}$ might increase the risk of cognitive impairment.

\section{Correspondence to:}

Dongfeng Zhang

Department of Epidemiology and Health Statistics

The School of Public Health of

Qingdao University

308 Ningxia Road

Qingdao

Shandong 266071

People's Republic of China

zhangdf1961@126.com
Air pollution, mainly particulate matter (PM) and gas pollutants [1], is one of the ten threats to global health in 2019, causing 7 million people dying prematurely every year [2]. Updated estimations from the World Health Organization (WHO) show that around 90\% of the worldwide people are breathing polluted air [3]. Hence, air pollution has become the greatest environmental hazard to public health.

Cognitive impairment, mainly encompassing both Alzheimer disease (AD) and dementia [4-6], is the $5^{\text {th }}$ leading cause of global death in 2016 [7], occurring nearly 10 million new cases every year [8]. The cause of cognitive impairment is considered to be a combination of genetic and environmental factors. As a modifiable environmental factor, air pollution plays a crucial role in central nervous system diseases, including cognitive impairment [9]. Accumulating animal studies indicated that air pollutants could lead to neuroinflammation and oxidative stress [9-11], which were involved in pathological evidence of cognitive impairment [12-16]. Based on these findings, many studies have evaluated the association between air pollution and cognitive impairment. Specifically, for $\mathrm{PM}_{2.5}$ exposure, a positive association was found in four studies [17-19], whereas no significant association was shown in other studies [20-25]. For $\mathrm{NO}_{2} / \mathrm{NO}_{\mathrm{x}}$ exposure, although the risk of cognitive impairment was illustrated in two studies $[17,18]$, the link was not manifested in 
other studies [20,21,25,26]. For $\mathrm{O}_{3}$ exposure, one study [17] revealed an inverse relationship with cognitive impairment, while another study [20] found a positive relationship with cognitive impairment. In light of the inconsistencies among the above epidemiological studies, we conducted a meta-analysis of longitudinal cohort studies to synthesize the results of existing studies to evaluate the relationship of air pollution with cognitive impairment.

\section{METHODS}

This meta-analysis was conducted according to the Preferred Reporting Items for Systematic reviews and Meta-Analyses (PRISMA) guidelines [27].

\section{Search strategy}

We searched all relevant articles in English or Chinese from PubMed, Web of Science and Wan Fang databases published between January 1950 and September 2019. The following search strategy was used: (air pollution or particulate matter or carbon monoxide or nitrogen dioxide or nitrogen oxide or sulfur dioxide or ozone) And (cognitive impairment or dementia). The exhaustive search process in PubMed is shown in Table S1 in the Online Supplementary Document. Furthermore, we reviewed the reference lists of retrieved articles to identify additional relevant articles.

\section{Inclusion criteria}

The included studies ought to meet the following criteria: (1) longitudinal cohort studies published in English or Chinese; (2) the exposure of interest was particulate $\left(\mathrm{PM}_{2.5}\right.$, particles with an aerodynamic diameter $\leq 2.5 \mu \mathrm{m} ; \mathrm{PM}_{10}$, particles with an aerodynamic diameter $\leq 10 \mu \mathrm{m}$ or $\mathrm{PM}_{2.5-10}$, particles with an aerodynamic diameter 2.5-10) or gaseous $\left(\mathrm{NO}_{2}\right.$, nitrogen dioxide; $\mathrm{NO}_{x}$, nitrogen oxide; $\mathrm{O}_{3}$, Ozone; $\mathrm{CO}$, carbon monoxide; $\mathrm{SO}_{2}$, sulfur dioxide) air pollutants; (3) the outcome of interest was cognitive impairment mainly including dementia and AD; (4) Multivariate adjusted odds ratio (OR), relative risk (RR) or hazard ratio (HR) and their 95\% confidence interval (CI) of cognitive impairment with exposures to air pollution with per unit increase in pollutant concentrations $\left(\mathrm{\mu g} / \mathrm{m}^{3}, \mathrm{mg} / \mathrm{m}^{3}, \mathrm{ppb}\right.$, or $\mathrm{ppm}$ ) were available, or sufficient data could be used to convert these results.

\section{Exclusion criteria}

(1) Review articles and studies were written in other languages instead of English or Chinese; (2) studies that did not estimate the relationship between air pollution and the risk of cognitive impairment; (3) results cannot be converted into RR and 95\% CI with per unit increase in particulate $\left(\mathrm{PM}_{2.5}, \mathrm{PM}_{10}\right.$, or $\left.\mathrm{PM}_{2.5-10}\right)$ or gaseous $\left(\mathrm{NO}_{2}, \mathrm{NO}_{\mathrm{x}}, \mathrm{O}_{3}, \mathrm{CO}, \mathrm{SO}_{2}\right.$ ) air pollutants concentrations $\left(\mu \mathrm{g} / \mathrm{m}^{3}, \mathrm{mg} / \mathrm{m}^{3}\right.$, ppb, or $\left.\mathrm{ppm}\right) ;(4) \mathrm{du}-$ plicated articles; (5) not cohort studies.

Two investigators independently performed the literature search. If there was disagreement on an article, the consensus was reached through discussion. If data appeared in more than one study, we would select the most comprehensive data.

\section{Data extraction}

Data extracted from each identified study by two investigators independently as follows: the first author's name, publication year, study areas and country, age range or mean age of participants, sex, follow-up duration, sample size, number of cases, measurement of exposure, the source of outcome, RRs (we presented all results with RR for simplicity) and their 95\% CI with per unit increase in particulate $\left(\mathrm{PM}_{2.5}\right.$, $\mathrm{PM}_{10}$, or $\left.\mathrm{PM}_{2.5-10}\right)$ or gaseous $\left(\mathrm{NO}_{2}, \mathrm{NO}_{x}, \mathrm{O}_{3}, \mathrm{CO}, \mathrm{SO}_{2}\right)$ air pollutants concentrations $\left(\mu \mathrm{g} / \mathrm{m}^{3}, \mathrm{mg} / \mathrm{m}^{3}, \mathrm{ppb}\right.$, or ppm), adjusted covariates.

The included cohort literature was assessed by the Newcastle-Ottawa Scale (NOS) [28].

\section{Statistical analysis}

We use the inverse variance and the number of participants to weight the study-specific log RRs that can calculate the pooled RR with corresponding 95\% CI to evaluate the relationship between air pollution and cognitive impairment. For consistency, all RRs were standardized to an increment of $5 \mu \mathrm{g} / \mathrm{m}^{3}$ of particular matter $\left(\mathrm{PM}_{2.5}, \mathrm{PM}_{2.5-10}\right.$, and $\left.\mathrm{PM}_{10}\right)$ concentration and $5 \mathrm{ppb}$ of gaseous $\left(\mathrm{NO}_{2}, \mathrm{NO}_{\mathrm{x}}, \mathrm{O}_{3}, \mathrm{CO}\right.$, 
$\mathrm{SO}_{2}$ ) concentration. It is hypothesized that there is a linear relationship of exposure to air pollution and cognitive impairment. If studies reported $\mathrm{RR}_{u}$ per $u$ units not in per $5 \mu \mathrm{g} / \mathrm{m}^{3}$ of particular matter $\left(\mathrm{PM}_{2.5}\right.$, $\mathrm{PM}_{2.5-10}$, and $\left.\mathrm{PM}_{10}\right)$ or $5 \mathrm{ppb}$ of gaseous $\left(\mathrm{NO}_{2}, \mathrm{NO}_{\mathrm{x}}, \mathrm{O}_{3}, \mathrm{CO}, \mathrm{SO}_{2}\right)$, the $\mathrm{RR}_{\text {standardized }}$ was computed by the following formula [29]:

$$
\mathrm{RR}_{\text {standardized }}=\mathrm{RR}_{u} \text { increment unit (eg, 5)/u }
$$

Where $\mathrm{u}$ represents the increment utilized in the original study to assess the effects. We used a unit conversion factor: $1 \mathrm{ppb}=1.88 \mu \mathrm{g} / \mathrm{m}^{3}$ for $\mathrm{NO}_{2} / \mathrm{NO}_{\mathrm{x}}$ and $1 \mathrm{ppb}=1.96 \mu \mathrm{g} / \mathrm{m}^{3}$ for $\mathrm{O}_{3}$, and standard condition is ambient pressure of 1 atmosphere and a temperature of $25^{\circ} \mathrm{C} \mathrm{[30].}$

We adopted to $I^{2}$ statistic to evaluate the heterogeneity, and the $I^{2}$ values of $0 \%, 25 \%, 50 \%$, and $75 \%$ represent no, low, moderate and high heterogeneity, respectively [31]. The random effect model (REM) was utilized as the pooling method. Meta-regression with restricted maximum likelihood estimation was used to explore the potential covariates that may exert substantial impacts on between-study heterogeneity [32]. Subgroup analysis was conducted by the source of outcome, study areas, follow-up duration, and adjustment status for comorbidity and smoking. We carried out the leave-one-out sensitivity analysis to examine whether individual study influences between-study heterogeneity [33]. Influence analysis was performed excluding one study at a time to ascertain whether the aggregate results could be significantly affected by a single study [34]. Additionally, the funnel plot and Egger regression asymmetry test were used to estimate the publication bias [35]. All statistical analyses were done using STATA Version 15.0 (STATA Corporation, College Station, TX, USA). A two-sided $P \leq 0.05$ was equated statistically significant.

\section{RESULTS}

\section{Search results and study characteristics}

On the basis of search strategy, a total of 11090 articles were identified, involving 1085 articles from PubMed, 382 articles from Web of Science, 9622 articles from Wan Fang and one article from reference lists. After removing 207 articles because of duplicates, there are 10883 articles left. Reviewing the title and abstract later, forty-one articles were remaining. We further excluded thirty-one articles after reviewing the full-text. The flow diagram of the literature search is displayed in Figure 1. The detailed reason for full-text reviewed articles exclusion is provided in Table S2 in the Online Supplementary Document.

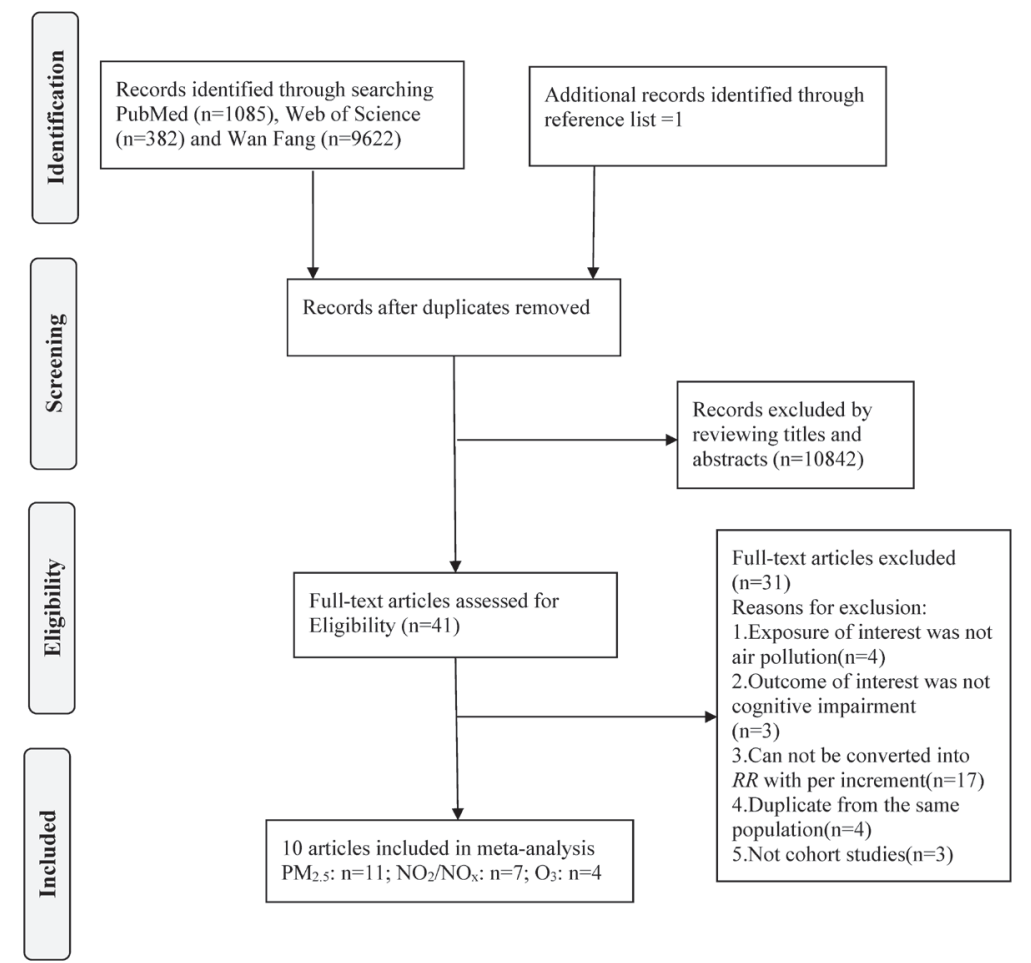

Figure 1. Flow diagram of the literature search for the study selection process. 
Ultimately, ten articles [17-26], including 11 studies on $\mathrm{PM}_{2.5}, 7$ studies on $\mathrm{NO}_{2} / \mathrm{NO}_{x}$ and 4 studies on $\mathrm{O}_{3}$, were satisfied the inclusion criteria and were enrolled in this meta-analysis. Eight articles [18,21-26] were population-based studies and two articles $[19,20]$ were hospital-based studies. The duration of follow-up ranged from 4 to 18 years, with three articles $[17,22,23]$ following equal to or less than 10 years and seven articles [18-21,24-26] more than 10 years. Concerning the study areas, four articles [17,20,24,26] were performed in Europe, five articles [18,19,21,23,25] in North America and one article [22] in Asia.

The quality assessment indicated that the Newcastle-Ottawa score of cohort studies was not less than 7 . Specific quality assessments are presented in Table S3 in the Online Supplementary Document. The characteristics of the studies are shown in Table 1.

\section{Quantitative synthesis}

Table 2 shows the summary risk estimates of cognitive impairment for air pollution according to study characteristics.

\section{$\mathbf{P M}_{2.5}$ exposure and the risk of cognitive impairment}

Eleven studies [17-25] comprising 519247 cases among 12523553 participants were included. The pooled RR of cognitive impairment per $5 \mu \mathrm{g} / \mathrm{m}^{3}$ increments in exposure to $\mathrm{PM}_{2.5}$ was 1.08 (95\% CI=1.03, 1.13; $I^{2}=82.2 \% ; P_{\text {heterogeneity }}<0.001$; Figure 2$)$. A positive significant association $\left(\operatorname{RR}_{\text {per }} 5 \mathrm{\mu g} / \mathrm{m}^{3}=1.36 ; 95 \%\right.$ $\mathrm{CI}=1.24,1.50 ; I^{2}=99.7 \%$; $P_{\text {hetergenenity }}<0.001$; Fig. $\mathrm{S} 1$ in the Online Supplementary Document) of cognitive impairment with $\mathrm{PM}_{2.5}$ exposure was found after sensitivity analysis with the number of participants as the weight.

We carried out subgroup analysis by the source of outcome, study areas, follow-up duration, and adjustment status for comorbidity and smoking. $\mathrm{PM}_{2.5}$ revealed a statistically significant positive association with the risk of cognitive impairment in population-based studies $\left(\mathrm{RR}_{\text {per } 5 \mu g / \mathrm{m}^{3}}=1.05 ; 95 \% \mathrm{CI}=1.01,1.09\right.$; $\left.I^{2}=57.4 \% ; P_{\text {heterogeneity }}=0.016\right)$, whereas no statistically significant association was found in hospital-based studies $\left(\mathrm{RR}_{\text {per } 5 \mathrm{\mu g} / \mathrm{m}^{3}}=1.20 ; 95 \% \mathrm{CI}=0.82,1.75 ; I^{2}=97.1 \% ; P_{\text {heterogeneity }}<0.001\right)$. Regarding study areas, the $\mathrm{RR}_{\text {per } 5 \mathrm{\mu g} / \mathrm{m}^{3}}$ were 1.13 (95\% CI $=1.01,1.26 ; I^{2}=86.7 \%$; $\left.P_{\text {heterogeneity }}<0.001\right)$ for studies conducted in North America, 1.34 (95\% CI =0.94, 1.89; $I^{2}=73.4 \%$; $\left.P_{\text {hetergenenity }}=0.005\right)$ in Europe and 1.10 (95\% CI=0.98, 1.04) in Asia. For follow-up duration, the $\mathrm{RR}_{\text {per } 5 \mathrm{\mu g} \mathrm{m}^{3}}$ were statistically significant among the studies with following duration $>10$ years $\left(\mathrm{RR}_{\text {per } 5 \mu \mathrm{g} / \mathrm{m}^{3}}=1.10 ; 95 \% \mathrm{CI}=1.03,1.17 ; \mathrm{I}^{2}=86.3 \% ; P_{\text {heterogeneity }}<0.001\right)$, while the association was not significant among the studies with following duration $\leq 10$ years $\left(\operatorname{RR}_{\text {per } 5 \mu \mathrm{g} / \mathrm{m}^{3}}=1.11\right.$; $\left.95 \% \mathrm{CI}=0.95,1.31 ; I^{2}=70.4 \% ; P_{\text {heterogeneity }}=0.018\right)$. There was a statistically significant positive relationship between $\mathrm{PM}_{2.5}$ and the risk of cognitive impairment in studies adjusting for comorbidity $\left(\operatorname{RR}_{\text {per } 5 \mu \mathrm{g} / \mathrm{m}^{3}}=1.10\right.$; $95 \% \mathrm{CI}=1.03,1.17 ; I^{2}=85.3 \% ; P_{\text {hetergenenity }}<0.001$ ), while no association was found in studies that did not adjust comorbidity $\left(\mathrm{RR}_{\text {per }} 5 \mu \mathrm{g} / \mathrm{m}^{3}=1.07 ; 95 \% \mathrm{CI}=0.90,1.26 ; I^{2}=64.1 \% ; P_{\text {heterogeneity }}=0.039\right)$. The combined $\mathrm{RR}_{\text {per } 5 \mathrm{\mu g} / \mathrm{m}^{3}}\left(\mathrm{RR}_{\text {per } 5 \mathrm{\mu g} / \mathrm{m}^{3}}=1.21 ; 95 \% \mathrm{CI}=1.00,1.46 ; \mathrm{I}^{2}=57.0 \% ; P_{\text {heterogeneity }}=0.040\right)$ in smoking-adjusted studies were higher than that $\left(\mathrm{RR}_{\text {per } 5 \mu \mathrm{m} / \mathrm{m}^{3}}=1.06 ; 95 \% \mathrm{CI}=1.01,1.11 ; \mathrm{I}^{2}=90.2 \% ; P_{\text {heterogeneiy }}<0.001\right)$ in studies that did not adjust for smoking.

\section{$\mathrm{NO}_{2} / \mathrm{NO}_{\mathrm{x}}$ exposure and the risk of cognitive impairment}

Seven studies [17,18,20,21,25,26] comprising 285752 cases among 2589907 participants were included. The pooled RR of cognitive impairment per 5 ppb increments in exposure to $\mathrm{NO}_{2} / \mathrm{NO}_{\mathrm{x}}$ was 1.02 (95\% $\mathrm{CI}=0.99,1.04 ; I^{2}=93.9 \% ; P_{\text {heterogeneity }}<0.001$; Figure 3$)$. A positive significant association $\left(\mathrm{RR}_{\text {per } 5 p p b}=1.03\right.$; 95\% CI $=1.02,1.04 ; I^{2}=96.9 \% ; P_{\text {heterogeneity }}<0.001$; Fig. S2 in the Online Supplementary Document) of cognitive impairment with $\mathrm{NO}_{2} / \mathrm{NO}_{\mathrm{x}}$ exposure was found after sensitivity analysis with the number of participants as the weight.

We carried out subgroup analysis by the source of outcome, study areas, follow-up duration, and adjustment status for comorbidity and smoking. $\mathrm{NO}_{2} / \mathrm{NO}_{x}$ revealed a statistically significant positive association with the risk of cognitive impairment in population-based studies $\left(\mathrm{RR}_{\text {per }} 5\right.$ ppb $=1.048 ; 95 \% \mathrm{CI}=1.004$, $\left.1.094 ; I^{2}=68.5 \% ; P_{\text {heterogeneity }}=0.013\right)$, whereas no association was found in hospital-based studies $\left(\mathrm{RR}_{\text {per } 5}\right.$ $\left.p p b=0.99 ; 95 \% \mathrm{CI}=0.95,1.02 ; I^{2}=94.7 \% ; P_{\text {heterogeneity }}<0.001\right)$. Regarding study areas, we didn't find relationship in either North America $\left(\mathrm{RR}_{\text {per }} 5 \mathrm{ppb}=1.03 ; 95 \% \mathrm{CI}=0.98,1.08 ; \mathrm{I}^{2}=66.4 \% ; P_{\text {heterogenenty }}=0.051\right)$ or Europe $\left(\mathrm{RR}_{\text {per }} 5\right.$ ppb $\left.=1.01 ; 95 \% \mathrm{CI}=0.98,1.05 ; \mathrm{I}^{2}=90.1 \% ; P_{\text {hetergeneity }}<0.001\right)$. There was no relationship between $\mathrm{NO}_{2} / \mathrm{NO}_{\mathrm{x}}$ and the risk of cognitive impairment both in studies adjusting for comorbidity $\left(\mathrm{RR}_{\text {per } 5 \text { ppb }}=1.04\right.$; $\left.95 \% \mathrm{CI}=0.99,1.09 ; I^{2}=72.6 \% ; P_{\text {heterogeneity }}=0.012\right)$ and not adjusting for comorbidity $\left(\operatorname{RR}_{\text {per }} 5 \mathrm{ppb}=1.00 ; 95 \%\right.$ 


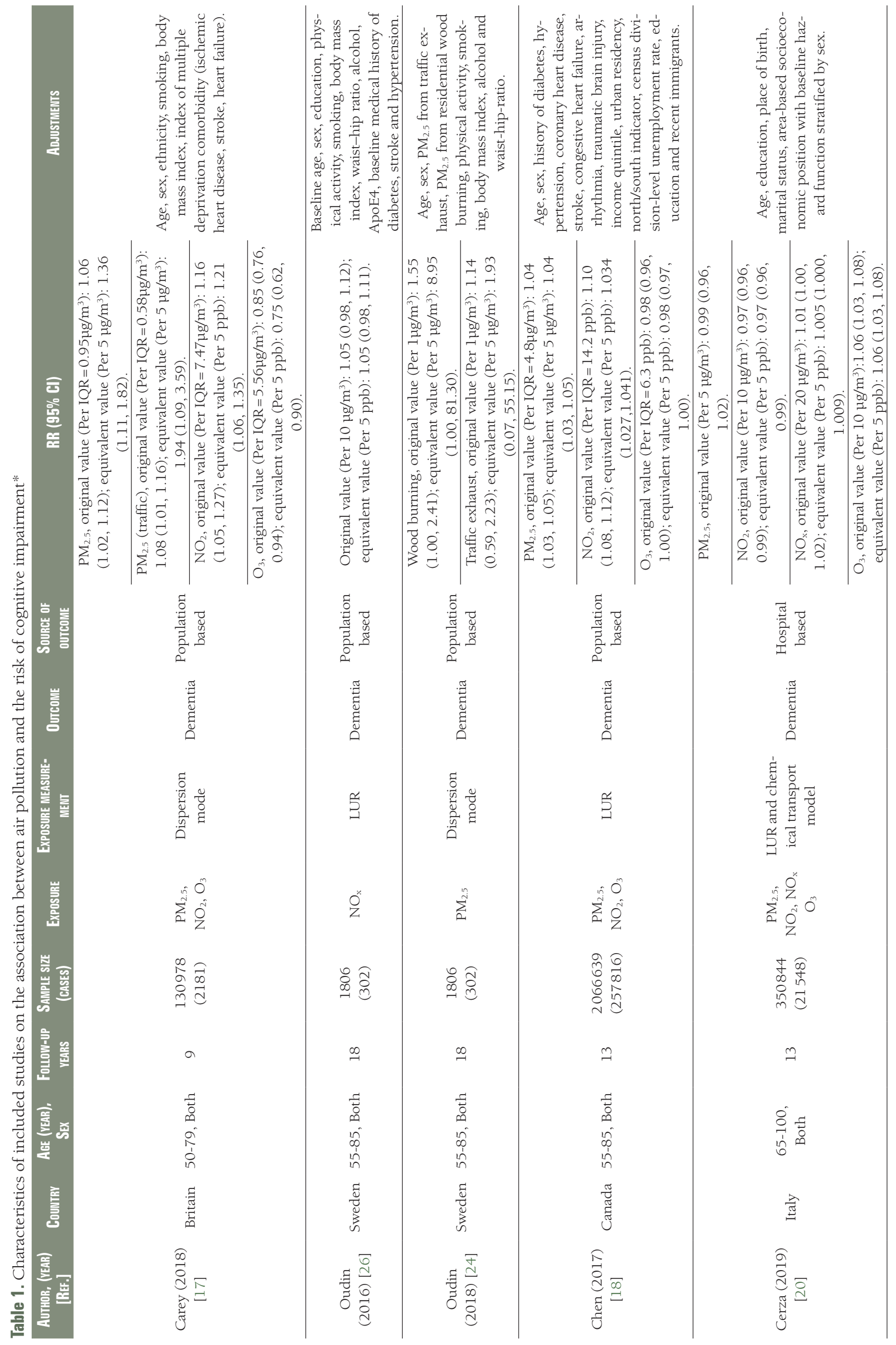



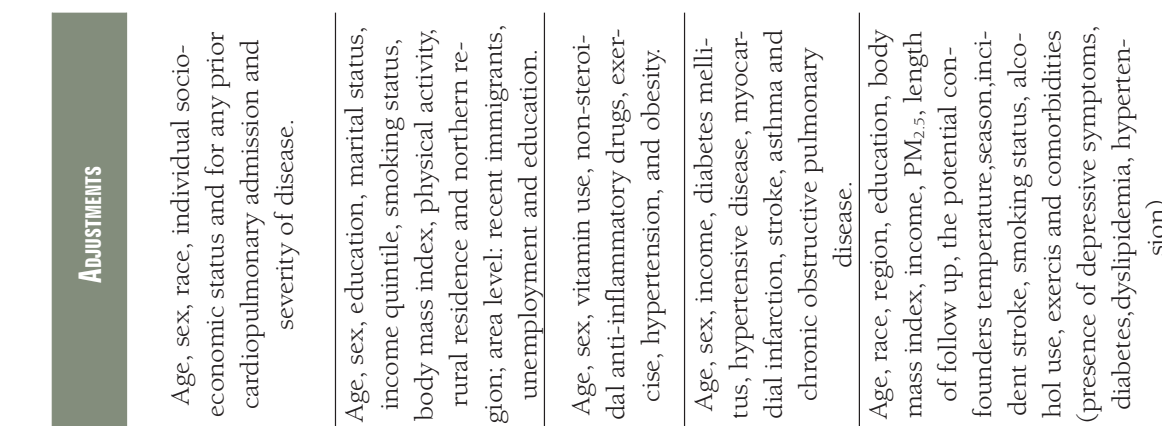

:

䓀

焉

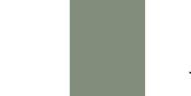

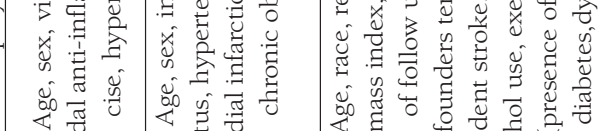

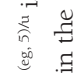

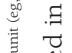

苛

要

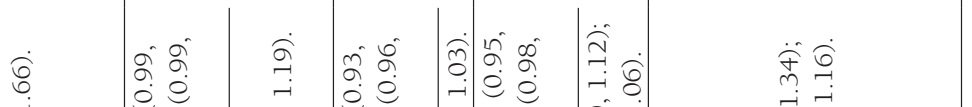

䜦

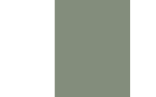

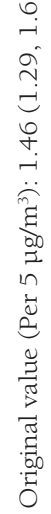

ì

aे

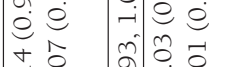

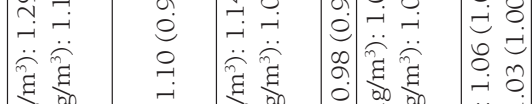

证娄

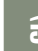

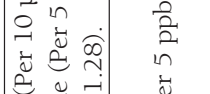

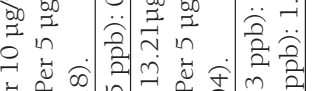

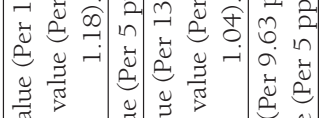

造

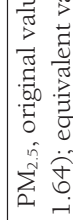

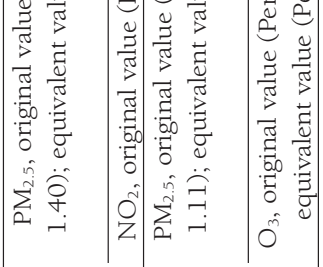

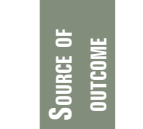

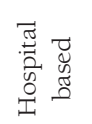

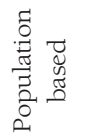

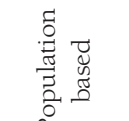

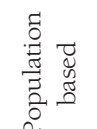

套

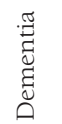

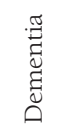

崖

b $\frac{1}{2}=$
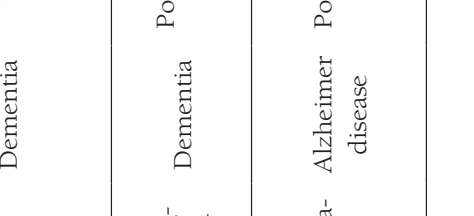

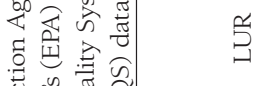

苧

⿳ㅗㅇ

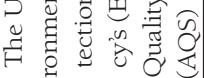

to

宸

$\sum_{n=1}^{n}$

言

跣

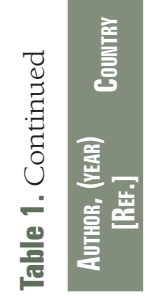

ஓ ิิ

$\begin{array}{ll}0 & 1 \\ 0 & 0 \\ 0 & 0 \\ 0 & 0 \\ 0 & d\end{array}$

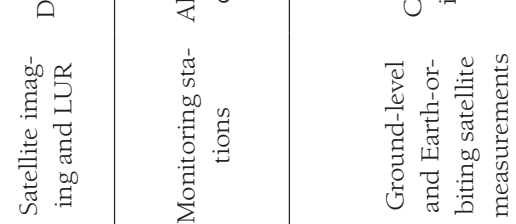

$\sum_{\substack{1 \\ Z}}^{2}$

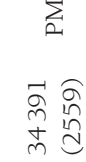

¿

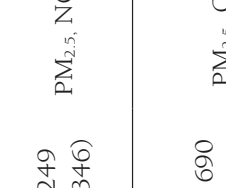

ฯ

害

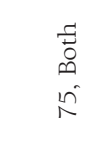

造

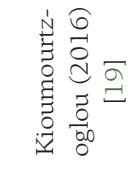

a

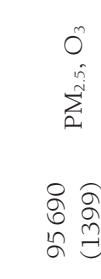

तi $\infty$

e

$\begin{array}{ll}\infty & 5 \\ \circ & 5 \\ 0 & 0\end{array}$

药

है

表苛

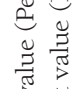

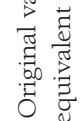

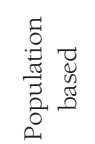

莺言节

告

告

苛

营

离节

륨ำ

돈

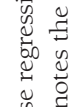

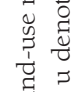

胥

告产

हु

$\begin{array}{ll}0 \\ 0 \\ 1 & 0 \\ 0 & 0 \\ 0 & 0 \\ 0 & 0 \\ 0 & 0\end{array}$

这

苛 气ै

苟毒

艾章

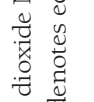

$\sum^{2}$

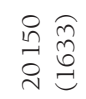

$\stackrel{\infty}{\sim}$

in $=$ a

$+$

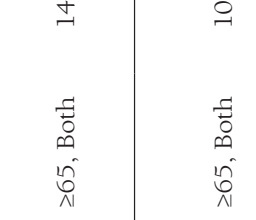

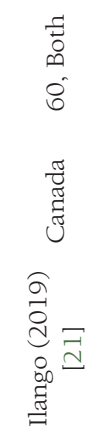

䘣

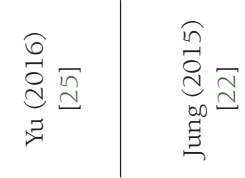

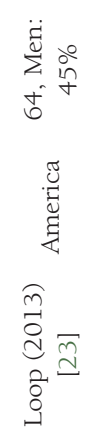

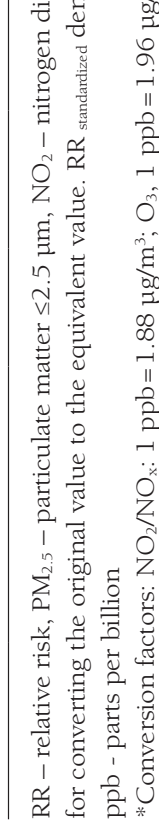


Table 2. Summary risk estimates of cognitive impairment for air pollution according to study characteristics

\begin{tabular}{|c|c|c|c|c|c|c|c|c|}
\hline Study Characteristics & $\begin{array}{c}\mathrm{PM}_{2.5} \\
\mathrm{~N}\end{array}$ & RR (95\% CI) & $R^{2}(\%)$ & 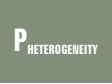 & $\begin{array}{c}\mathrm{NO}_{2} / \mathrm{NO}_{\mathrm{x}} \\
\mathbb{N}\end{array}$ & RR (95\% CI) & $R^{2}(\%)$ & $\mathbf{P}_{\text {Heाrousantry }}$ \\
\hline All studies & 11 & $1.08(1.03,1.13)$ & $82.2 \%$ & $<0.001$ & 7 & $1.02(0.99,1.04)$ & $93.4 \%$ & $<0.001$ \\
\hline \multicolumn{9}{|c|}{ Source of outcome: } \\
\hline Population-based & 9 & $1.05(1.01,1.09)$ & $57.4 \%$ & 0.016 & 5 & $1.048(1.004,1.094)$ & $68.5 \%$ & 0.013 \\
\hline Hospital-based & 2 & $1.20(0.82,1.75)$ & $97.1 \%$ & $<0.001$ & 2 & $0.99(0.95,1.02)$ & $94.7 \%$ & $<0.001$ \\
\hline \multicolumn{9}{|l|}{ Study areas: } \\
\hline Europe & 5 & $1.34(0.94,1.89)$ & $73.4 \%$ & 0.005 & 4 & $1.01(0.98,1.05)$ & $90.1 \%$ & $<0.001$ \\
\hline North America & 5 & $1.13(1.01,1.26)$ & $86.7 \%$ & $<0.001$ & 3 & $1.03(0.98,1.08)$ & $66.4 \%$ & 0.051 \\
\hline Asia & 1 & $1.01(0.98,1.04)$ & I & I & & & & \\
\hline \multicolumn{9}{|c|}{ Follow-up duration: } \\
\hline$\leq 10$ & 4 & $1.11(0.95,1.31)$ & $70.4 \%$ & 0.018 & 1 & $1.21(1.06,1.35)$ & 1 & I \\
\hline$>10$ & 7 & $1.10(1.03,1.17)$ & $86.3 \%$ & $<0.001$ & 4 & $1.01(0.99,1.03)$ & $94.4 \%$ & $<0.001$ \\
\hline \multicolumn{9}{|c|}{ Adjusted comorbidity: } \\
\hline Yes & 7 & $1.10(1.03,1.17)$ & $85.3 \%$ & $<0.001$ & 4 & $1.04(0.99,1.09)$ & $72.6 \%$ & 0.012 \\
\hline No & 4 & $1.07(0.90,1.26)$ & $64.1 \%$ & 0.039 & 3 & $1.00(0.97,1.04)$ & $91.2 \%$ & $<0.001$ \\
\hline \multicolumn{9}{|c|}{ Adjusted smoking: } \\
\hline Yes & 6 & $1.21(1.00,1.46)$ & $57.0 \%$ & 0.040 & 3 & $1.10(1.02,1.19)$ & $53.2 \%$ & 0.118 \\
\hline No & 5 & $1.06(1.01,1.11)$ & $90.2 \%$ & $<0.001$ & 4 & $1.00(0.98,1.03)$ & $96.5 \%$ & $<0.001$ \\
\hline
\end{tabular}

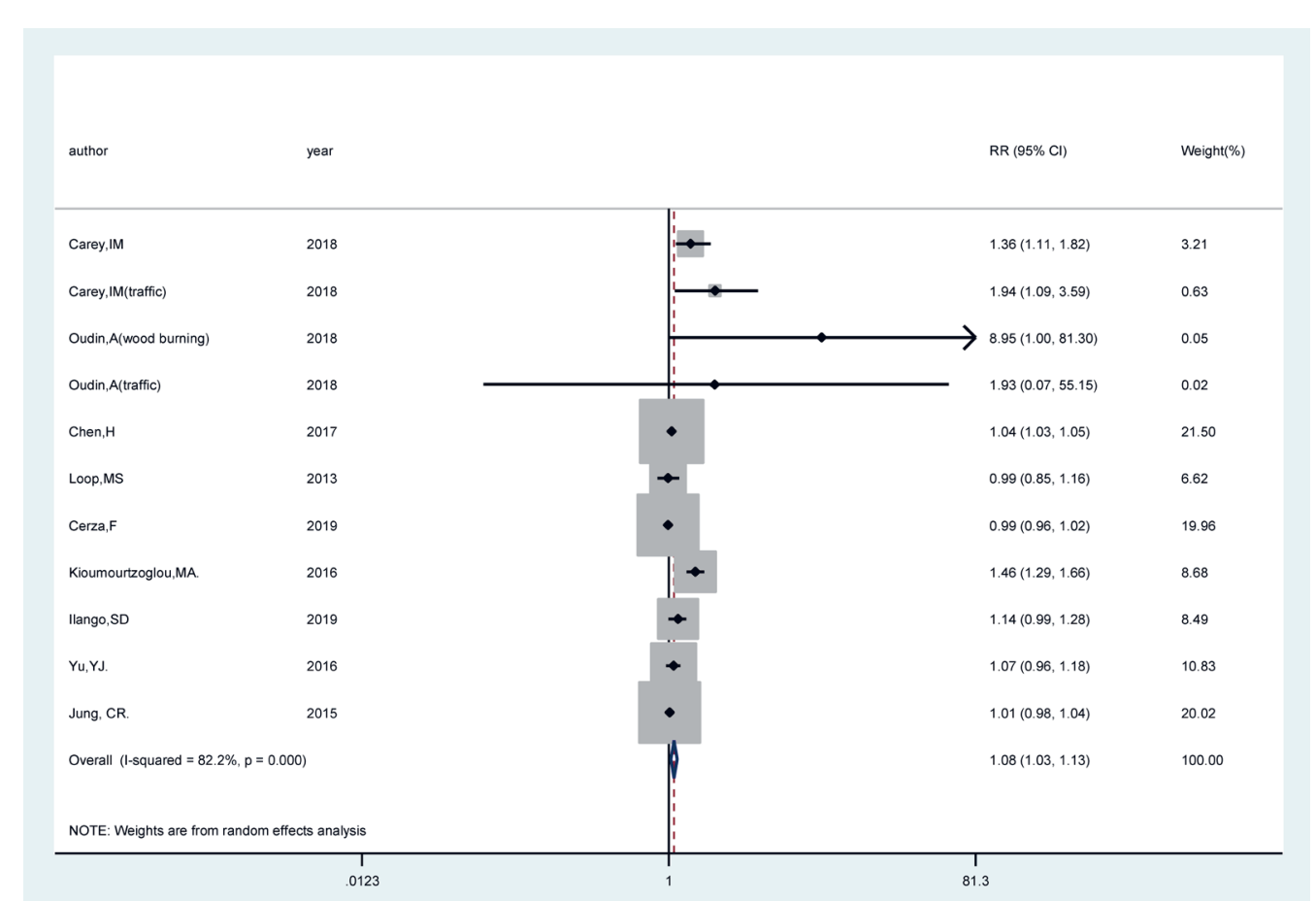

Figure 2. Forest plot for the pooled relative ratio (RR) and $95 \%$ confidence interval (CI) of studies on $\mathrm{PM}_{2.5}$ exposure (per $5 \mu \mathrm{g} / \mathrm{m}^{3}$ increment) with cognitive impairment. The size of the gray box is positively proportional to the weight assigned to each study, and horizontal lines represent the 95\% CI.

$\left.\mathrm{CI}=0.97,1.04 ; I^{2}=91.2 \% ; P_{\text {heterogeneity }}<0.001\right)$. The combined $\mathrm{RR}_{\text {per } 5 \text { ppb }}$ were statistically significant $\left(\mathrm{RR}_{\text {per }} 5\right.$ $\left.p p b=1.10 ; 95 \% C I=1.02,1.19 ; I^{2}=53.2 \% ; P_{\text {hetergenenity }}=0.118\right)$ in smoking-adjusted studies, but not in studies that did not adjust for smoking $\left(\mathrm{RR}_{p e r} 5 \mathrm{ppb}=1.00 ; 95 \% \mathrm{CI}=0.98,1.03 ; I^{2}=96.5 \% ; P_{\text {heterogeneity }}<0.001\right)$.

\section{$\mathrm{O}_{3}$ exposure and the risk of cognitive impairment}

Four studies [17,18,20,22] comprising 282944 cases among 2644151 participants were included. The pooled RR of cognitive impairment per 5 ppb increments in exposure to $\mathrm{O}_{3}$ was 1.00 ( $95 \% \mathrm{CI}=0.95,1.06$; $I^{2}=92.9 \% ; P_{\text {heterogeneity }}<0.001$; Figure 4). An inverse significant association $\left(\operatorname{RR}_{\text {per } 5 p p b}=0.98 ; 95 \% \mathrm{CI}=0.96\right.$, 


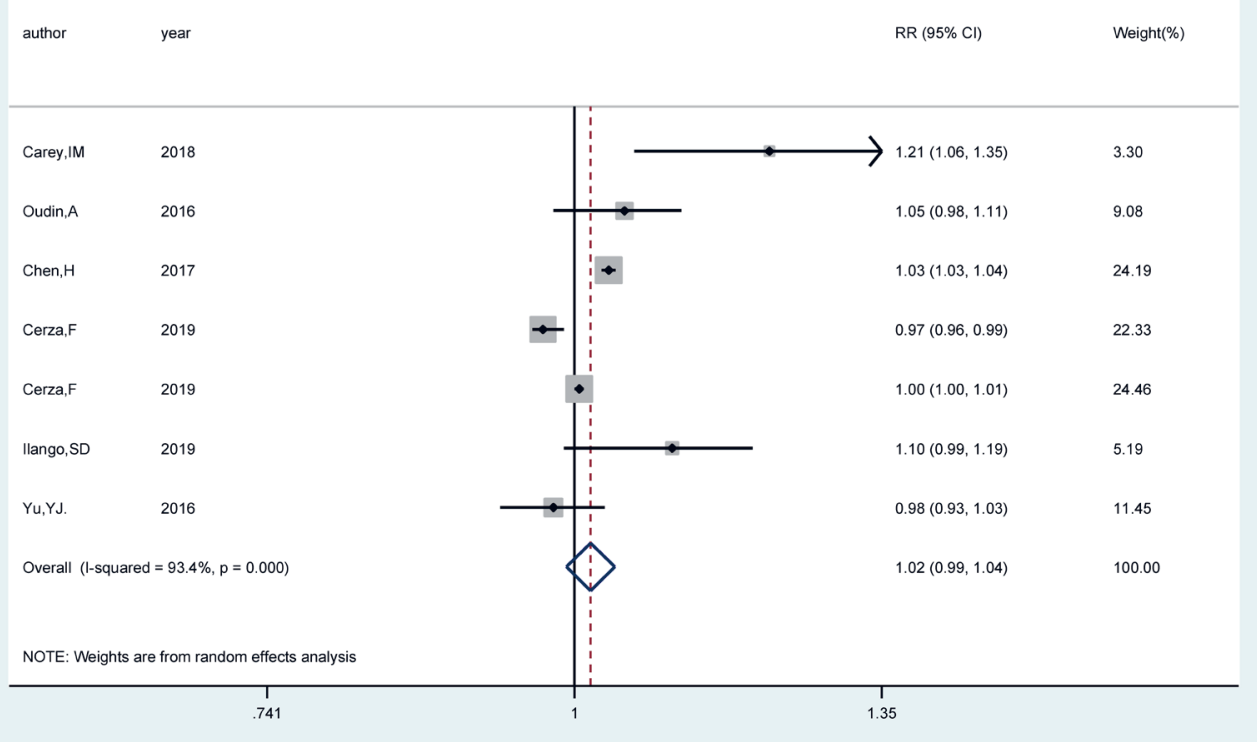

Figure 3. Forest plot for the pooled relative ratio (RR) and $95 \%$ confidence interval (CI) of studies on $\mathrm{NO}_{2} / \mathrm{NO}_{\mathrm{x}}$ exposure (per $5 \mathrm{ppb}$ increment) with cognitive impairment. The size of the gray box is positively proportional to the weight assigned to each study, and horizontal lines represent the 95\% CI.

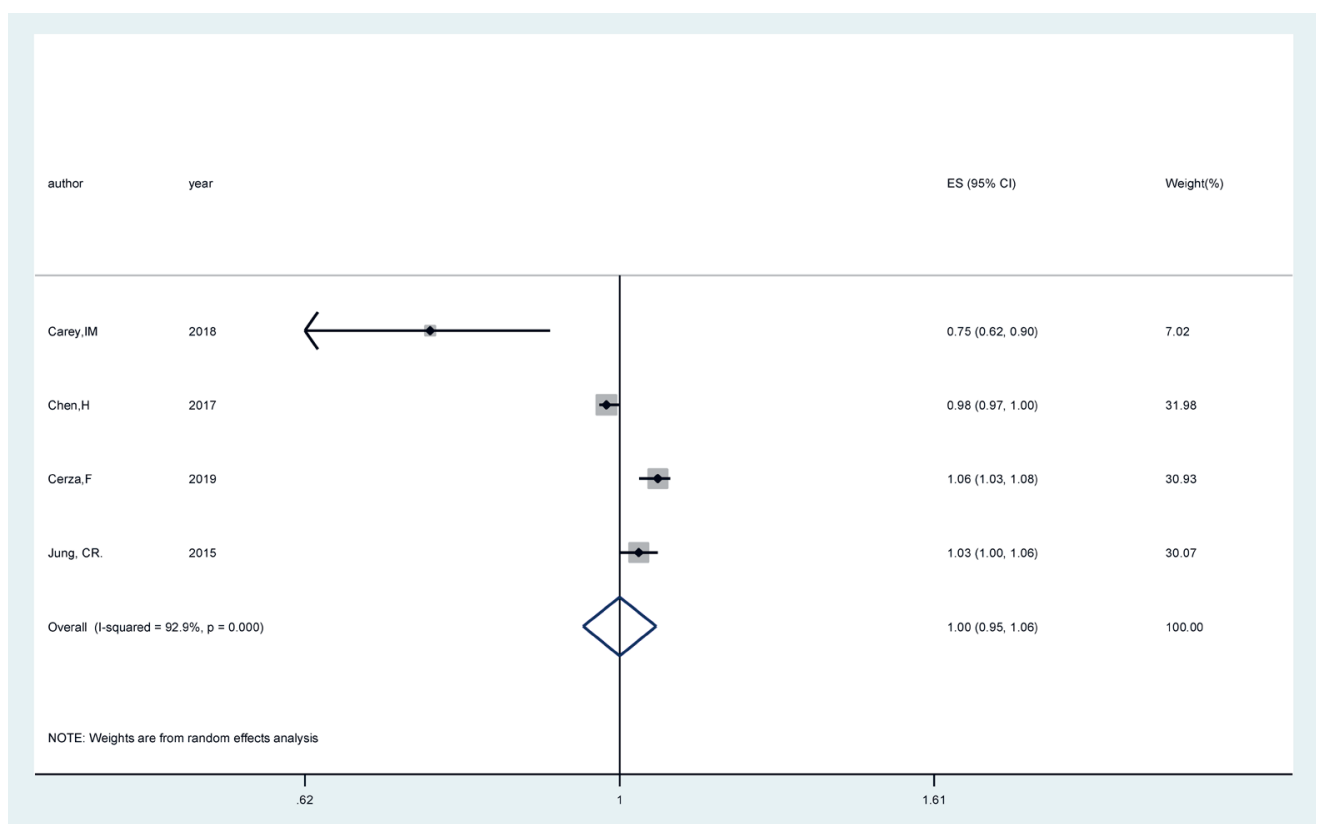

Figure 4. Forest plot for the pooled relative ratio (RR) and $95 \%$ confidence interval (CI) of studies on $\mathrm{O}_{3}$ exposure (per $5 \mathrm{ppb}$ increment) with cognitive impairment. The size of the gray box is positively proportional to the weight assigned to each study, and horizontal lines represent the 95\% CI.

0.99; $I^{2}=95.2 \%$; Phetergeneity $<0.001$; Fig.S3 in the Online Supplementary Document) of cognitive impairment with $\mathrm{O}_{3}$ exposure was found after sensitivity analysis with the number of participants as the weight.

\section{Meta-regression}

As displayed in Figure 2, high heterogeneity $\left(I^{2}=82.8 \%, P_{\text {heterogeneity }}=0.030\right)$ was found in the analysis of $\mathrm{PM}_{2.5}$ and the risk of cognitive impairment. Hence, we performed meta-regression with the covariates of 
the source of outcome $(P=0.663)$, study areas $(P=0.403)$, follow-up duration $(P=0.993)$, whether adjusted comorbidity $(P=0.679)$ and whether adjusted smoking $(P=0.475)$ to explore potential sources of the heterogeneity. However, no covariates contributed to the heterogeneity of between-study.

In the analysis of $\mathrm{NO}_{2} / \mathrm{NO}_{\mathrm{x}}$ and the risk of cognitive impairment, as displayed in Figure 3 high heterogeneity $\left(I^{2}=93.4 \%, P_{\text {heterogeneity }}<0.001\right)$ was found. The meta-regression with the covariates of the source of outcome $(P=0.219)$, study areas $(P=0.065)$, follow-up duration $(P=0.053)$, whether adjusted comorbidity $(P=0.979)$ and whether adjusted smoking $(P=0.540)$ to explore potential sources of the heterogeneity, and no covariates contributed to the heterogeneity.

\section{Sensitivity analysis and influence analysis}

For the $\mathrm{PM}_{2.5}$ exposure and the risk of cognitive impairment, we carried out the leave-one-out sensitivity analysis. After excluding two studies $[19,20], I^{2}$ decreased from $82.2 \%$ to $57.4 \%(P=0.016)$, and the result remained significant $\left(\mathrm{RR}_{\text {per }} 5 \mathrm{\mu g} / \mathrm{m}^{3}=1.05 ; 95 \% \mathrm{CI}=1.01,1.09\right.$; Figure $\mathrm{S} 4$ in the Online Supplementary Document).

In the influence analysis, no individual study had an overmuch impact on the pooled effect for $\mathrm{PM}_{2.5}$ and $\mathrm{NO}_{2} / \mathrm{NO}_{\mathrm{x}}$ with the risk of cognitive impairment (Figure $\mathrm{S} 5$ in the Online Supplementary Document and Figure S6 in the Online Supplementary Document).

\section{Publication bias}

The visual scrutiny of the funnel plot (Figure S7 in the Online Supplementary Document and Figure S8 in the Online Supplementary Document) seemed to be asymmetrical for $\mathrm{PM}_{2.5}$ and $\mathrm{NO}_{2} / \mathrm{NO}_{\mathrm{x}}$, while the Egger's test displayed no evidence of significant publication bias in the analysis between $\mathrm{PM}_{2.5}(P=0.155)$ and $\mathrm{NO}_{2} / \mathrm{NO}_{\mathrm{x}}(P=0.792)$ and the risk of cognitive impairment, respectively.

\section{DISCUSSION}

This meta-analysis of longitudinal cohort studies included 10 articles to quantitatively evaluate the association between air pollution exposure and the risk of cognitive impairment. The results demonstrated that exposure to $\mathrm{PM}_{2.5}$ was significantly related to an increased risk of cognitive impairment. More specifically, for every $5 \mu \mathrm{g} / \mathrm{m}^{3}$ increase in $\mathrm{PM}_{2.5}$ concentration, the risk of cognitive impairment increased by $8 \%$. Nevertheless, there is no statistical association between $\mathrm{NO}_{2} / \mathrm{NO}_{x}$ and $\mathrm{O}_{3}$ exposure and the risk of cognitive impairment. And the correlation direction did not change after sensitivity analysis. For $\mathrm{PM}_{2.5}$ exposure, subgroup analysis showed significant associations in population-based studies, studies that conducted in North America and studies with follow-up duration $>10$ years.

Several biological mechanisms have been put forward for the positive relationship of particulate matter (PM) with cognitive impairment. First, exposure to air pollution, particularly PM might cause neuroinflammation, oxidative stress and change brain innate immune responses in early adulthood [36]. At present, inflammation and oxidative stress have been confirmed as basic mechanisms by which air pollution may affect central nervous system disease (CNS) [9]. Second, PM can activate microglia [37], excessive and chronic activation may lead to neurotoxicity [38]. Importantly, microglial activation has been implicated in the progression of diseases such as dementia [39]. Third, the olfactory bulb is another pathway [40] through which PM enters the body, reaching the brain directly and inducing a series of changes such as increased the level of amyloid- $\beta 42$, hyperphosphorylated $\tau$, and neural degeneration [41,42].

High heterogeneity appeared in this meta-analysis of $\mathrm{PM}_{2.5}$ and $\mathrm{NO}_{2} / \mathrm{NO}_{\mathrm{x}}$ and the risk of cognitive impairment. To search for potential heterogeneity, we performed the following work. Meta-regression was performed to detect the potential factors that contributed to heterogeneity between studies, however, no factors were found to do with it. We also conducted influence analysis, and the results indicated that no individual study had an excessive impact on the pooled effect of $\mathrm{PM}_{2.5}$ and $\mathrm{NO}_{2} / \mathrm{NO}_{\mathrm{x}}$ and the risk of cognitive impairment. For $\mathrm{PM}_{2.5}$ exposure, the leave-one-out sensitivity analysis indicated that two studies $[19,20]$ affected the heterogeneity and after further excluding two studies, the pooled RR was decreased but not altered substantially. In two studies, the source of outcome was from the hospital-based population, which was likely to not cover all patients and could introduce selection bias.

Our study presents several advantages. First, our meta-analysis included a large number of participants from longitudinal cohort studies, providing high statistical power and making it more likely to obtain a 
reasonable conclusion. Second, the pooled RR of this meta-analysis was based on data on dose-response relationships in the original studies, thus the existence of causation was further supported. Furthermore, to minimize between-study variation, we normalized the exposure levels of $\mathrm{PM}_{2.5}, \mathrm{NO}_{2} / \mathrm{NO}_{\mathrm{x}}$ and $\mathrm{O}_{3}$ across studies into uniform units, and the pooled RR was standardized per $5 \mu \mathrm{g} / \mathrm{m}^{3}$ increments for $\mathrm{PM}_{2.5}$ and 5 $\mathrm{ppb}$ for $\mathrm{NO}_{2} / \mathrm{NO}_{x}$ and $\mathrm{O}_{3}$. Third, original studies were all fully taken into account potential confounders such as age. Moreover, sex, comorbidities, and smoking were adjusted for in most studies. As well, the quality assessment score of each study was higher than 7 , demonstrating that the quality of the included articles was generally good.

Nevertheless, several limitations of our meta-analysis should be recognized. First, although as much as possible potential confounders were adjusted for in most studies, several studies still did not adjust for potential confounders, such as comorbidities. Comorbidities include heart disease, stroke, diabetes, hypertension and so on, which may elevate cognitive impairment risk [43-45]. In the analysis of $\mathrm{PM}_{2.5}$ and cognitive impairment, a significant association was found in studies adjusting for comorbidity, but no association was found in studies that did not adjust for comorbidity, therefore the combined result was underestimated. Second, varied exposure assessment methods differed in its ability to provide estimates of individual exposure levels, which might increase the instability of the results to some extent. Third, the definition of cognitive impairment was inconsistent, resulting in misclassification bias.

\section{CONCLUSIONS}

In summary, the results of this meta-analysis demonstrated that exposure to $\mathrm{PM}_{2.5}$ was associated with an increase in cognitive impairment risk. The results may have substantial public health significance for the prevention of cognitive impairment through air pollution interventions.

\footnotetext{
Funding: None.
Author's contribution: XY and DZ designed the study, participated in its design and coordination, interpre-
tation of the data and involved in drafting the manuscript. XY, DZ and WJ involved in revising it critically for
important intellectual content. XY, and LZ performed the bibliographical search, data extraction and interpre-
tation of the data.
Competing interests: The authors completed the Unified Competing Interest form at www.icmje.org/coi_dis-
closure.pdf (available upon request from the corresponding author), and declare no conflicts of interest.
Additional material
Online Supplementary Document
}

1 Dickey JH. Part VII. Air pollution: overview of sources and health effects. Dis Mon. 2000;46:566-89. Medline:11021547 doi:10.1016/S0011-5029(00)90024-5

2 World Health Organization. 2019. Ten threats to global health in 2019. Available: https://www.who.int/emergencies/tenthreats-to-global-health-in-2019. 2019. Accessed: 15 October 2019.

3 World Health Organization. 9 out of 10 people worldwide breathe polluted air, but more countries are taking action. Available: https://www.who.int/news-room/detail/02-05-2018-9-out-of-10-people-worldwide-breathe-polluted-air-butmore-countries-are-taking-action. 2019. Accessed: 15 October 2019.

4 Duron E, Hanon O. Vascular risk factors, cognitive decline, and dementia. Vasc Health Risk Manag. 2008;4:363-81. Medline:18561512 doi:10.2147/NHRM.S1839

5 Hachinski V, Iadecola C, Petersen RC, Breteler MM, Nyenhuis DL, Black SE, et al. National Institute of Neurological Disorders and Stroke-Canadian Stroke Network vascular cognitive impairment harmonization standards. Stroke. 2006;37:2220-41. Medline:16917086 doi:10.1161/01.STR.0000237236.88823.47

6 Morris JC, Storandt M, Miller JP, McKeel DW, Price JL, Rubin EH, et al. Mild cognitive impairment represents early-stage Alzheimer disease. Arch Neurol. 2001;58:397-405. Medline:11255443 doi:10.1001/archneur.58.3.397

7 World Health Organization. 2019. The top ten causes of death. Available: https://www.who.int/en/news-room/fact-sheets/ detail/the-top-10-causes-of-death. Accessed: 15 October 2019.

8 World Health Organization. Dementia. 2019. Available: https://www.who.int/news-room/fact-sheets/detail/dementia. Accessed October 15, 2019.

9 Block ML, Calderon-Garciduenas L. Air pollution: mechanisms of neuroinflammation and CNS disease. Trends Neurosci. 2009;32:506-16. Medline:19716187 doi:10.1016/j.tins.2009.05.009 
10 Genc S, Zadeoglulari Z, Fuss SH, Genc K. The adverse effects of air pollution on the nervous system. J Toxicol. 2012;2012:782462. Medline:22523490 doi:10.1155/2012/782462

11 González-Flecha B. Oxidant mechanisms in response to ambient air particles. Mol Aspects Med. 2004;25:169-82. Medline:15051325 doi:10.1016/j.mam.2004.02.017

12 Bonda DJ, Wang X, Perry G, Nunomura A, Tabaton M, Zhu X, et al. Oxidative stress in Alzheimer disease: a possibility for prevention. Neuropharmacology. 2010;59:290-4. Medline:20394761 doi:10.1016/j.neuropharm.2010.04.005

13 Hoozemans JJ, Veerhuis R, Rozemuller JM, Eikelenboom P. Neuroinflammation and regeneration in the early stages of Alzheimer's disease pathology. Int J Dev Neurosci. 2006;24:157-65. Medline:16384684 doi:10.1016/j.ijdevneu.2005.11.001

14 Minghetti L. Role of inflammation in neurodegenerative diseases. Curr Opin Neurol. 2005;18:315-21. Medline:15891419 doi:10.1097/01.wco.0000169752.54191.97

15 Su B, Wang X, Nunomura A, Moreira PI, Lee H-g, Perry G, et al. Oxidative stress signaling in Alzheimer's disease. Curr Alzheimer Res. 2008;5:525-32. Medline:19075578 doi:10.2174/156720508786898451

16 Zhu X, Raina AK, Lee H-g, Casadesus G, Smith MA, Perry G. Oxidative stress signalling in Alzheimer's disease. Brain Res. 2004;1000:32-9. Medline:15053949 doi:10.1016/j.brainres.2004.01.012

17 Carey IM, Anderson HR, Atkinson RW, Beevers SD, Cook DG, Strachan DP, et al. Are noise and air pollution related to the incidence of dementia? A cohort study in London, England. BMJ Open. 2018;8:e022404. Medline:30206085 doi:10.1136/bmjopen-2018-022404

18 Chen H, Kwong JC, Copes R, Hystad P, van Donkelaar A, Tu K, et al. Exposure to ambient air pollution and the incidence of dementia: A population-based cohort study. Environ Int. 2017;108:271-7. Medline:28917207 doi:10.1016/j. envint.2017.08.020

19 Kioumourtzoglou MA, Schwartz JD, Weisskopf MG, Melly SJ, Wang Y, Dominici F, et al. Long-term PM2.5 Exposure and Neurological Hospital Admissions in the Northeastern United States. Environ Health Perspect. 2016;124:23-9. Medline:25978701 doi:10.1289/ehp.1408973

20 Cerza F, Renzi M, Gariazzo C, Davoli M, Michelozzi P, Forastiere F, et al. Long-term exposure to air pollution and hospitalization for dementia in the Rome longitudinal study. Environ Health. 2019;18:72. Medline:31399053 doi:10.1186/ s12940-019-0511-5

21 Ilango SD, Chen H, Hystad P, van Donkelaar A, Kwong JC, Tu K, et al. The role of cardiovascular disease in the relationship between air pollution and incident dementia: a population-based cohort study. Int J Epidemiol. 2019;Jul 25:dyz154 [Epub ahead of print]. Medline:31347651 doi:10.1093/ije/dyz154

22 Jung CR, Lin YT, Hwang BF. Ozone, particulate matter, and newly diagnosed Alzheimer's disease: a population-based cohort study in Taiwan. J Alzheimers Dis. 2015;44:573-84. Medline:25310992 doi:10.3233/JAD-140855

23 Loop MS, Kent ST, Al-Hamdan MZ, Crosson WL, Estes SM, Estes MG Jr, et al. Fine particulate matter and incident cognitive impairment in the REasons for Geographic and Racial Differences in Stroke (REGARDS) cohort. PLoS One. 2013;8:e75001. Medline:24086422 doi:10.1371/journal.pone.0075001

24 Oudin A, Segersson D, Adolfsson R, Forsberg B. Association between air pollution from residential wood burning and dementia incidence in a longitudinal study in Northern Sweden. PLoS One. 2018;13:e0198283. Medline:29897947 doi:10.1371/journal.pone.0198283

$25 \mathrm{Yu}$ Y. Associations between long term exposure to air pollution and the incidence of dementia and cognitive impairment in a Canadian prospective cohort study [dissertation]. Carleton University: Carleton University; 2016.

26 Oudin A, Forsberg B, Adolfsson AN, Lind N, Modig L, Nordin M, et al. Traffic-Related Air Pollution and Dementia Incidence in Northern Sweden: A Longitudinal Study. Environ Health Perspect. 2016;124:306-12. Medline:26305859 doi:10.1289/ehp. 1408322

27 Moher D, Liberati A, Tetzlaff J, Altman DG. Preferred reporting items for systematic reviews and meta-analyses: the PRISMA statement. Ann Intern Med. 2009;151:264-9. Medline:19622511 doi:10.7326/0003-4819-151-4-200908180-00135

28 Zeng X, Zhang Y, Kwong JS, Zhang C, Li S, Sun F, et al. The methodological quality assessment tools for preclinical and clinical studies, systematic review and meta-analysis, and clinical practice guideline: a systematic review. J Evid Based Med. 2015;8:2-10. Medline:25594108 doi:10.1111/jebm.12141

29 Nhung NTT, Amini H, Schindler C, Kutlar Joss M, Dien TM, Probst-Hensch N, et al. Short-term association between ambient air pollution and pneumonia in children: A systematic review and meta-analysis of time-series and case-crossover studies. Environ Pollut. 2017;230:1000-8. Medline:28763933 doi:10.1016/j.envpol.2017.07.063

30 Vrijheid M, Martinez D, Manzanares S, Dadvand P, Schembari A, Rankin J, et al. Ambient air pollution and risk of congenital anomalies: a systematic review and meta-analysis. Environ Health Perspect. 2011;119:598-606. Medline:21131253 doi:10.1289/ehp. 1002946

31 Higgins JP, Thompson SG. Quantifying heterogeneity in a meta-analysis. Stat Med. 2002;21:1539-58. Medline:12111919 doi:10.1002/sim.1186

32 Higgins JP, Thompson SG. Controlling the risk of spurious findings from meta-regression. Stat Med. 2004;23:1663-82. Medline:15160401 doi:10.1002/sim.1752

33 Patsopoulos NA, Evangelou E, Ioannidis JP. Sensitivity of between-study heterogeneity in meta-analysis: proposed metrics and empirical evaluation. Int J Epidemiol. 2008;37:1148-57. Medline:18424475 doi:10.1093/ije/dyn065

34 Tobias A. Assessing the influence of a single study in the meta-analysis estimate. Stata Tech Bull. 1999;47:15-7.

35 Egger M, Davey Smith G, Schneider M, Minder C. Bias in meta-analysis detected by a simple, graphical test. BMJ. 1997;315:629-34. Medline:9310563 doi:10.1136/bmj.315.7109.629 
36 Calderón-Garcidueñas L, Solt AC, Henriquez-Roldan C, Torres-Jardon R, Nuse B, Herritt L, et al. Long-term air pollution exposure is associated with neuroinflammation, an altered innate immune response, disruption of the blood-brain barrier, ultrafine particulate deposition, and accumulation of amyloid beta-42 and alpha-synuclein in children and young adults. Toxicol Pathol. 2008;36:289-310. Medline:18349428 doi:10.1177/0192623307313011

37 Levesque S, Taetzsch T, Lull ME, Kodavanti U, Stadler K, Wagner A, et al. Diesel exhaust activates and primes microglia: air pollution, neuroinflammation, and regulation of dopaminergic neurotoxicity. Environ Health Perspect. 2011;119:114955. Medline:21561831 doi:10.1289/ehp.1002986

38 Block ML, Hong JS. Chronic microglial activation and progressive dopaminergic neurotoxicity. Biochem Soc Trans. 2007;35:1127-32. Medline:17956294 doi:10.1042/BST0351127

39 McGeer PL, Itagaki S, Boyes BE, McGeer EG. Reactive microglia are positive for HLA-DR in the substantia nigra of Parkinson's and Alzheimer's disease brains. Neurology. 1988;38:1285-91. Medline:3399080 doi:10.1212/WNL.38.8.1285

40 Calderón-Garcidueñas L, Franco-Lira M, Henriquez-Roldan C, Osnaya N, Gonzalez-Maciel A, Reynoso-Robles R, et al. Urban air pollution: influences on olfactory function and pathology in exposed children and young adults. Exp Toxicol Pathol. 2010;62:91-102. Medline:19297138 doi:10.1016/j.etp.2009.02.117

41 Kim SH, Knight EM, Saunders EL, Cuevas AK, Popovech M, Chen LC, et al. Rapid doubling of Alzheimer's amyloid- $\beta 40$ and 42 levels in brains of mice exposed to a nickel nanoparticle model of air pollution. F1000 Res. 2012;1:70. doi:10.12688/f1000research.1-70.v1

42 Block ML, Elder A, Auten RL, Bilbo SD, Chen H, Chen JC, et al. The outdoor air pollution and brain health workshop. Neurotoxicology. 2012;33:972-84. Medline:22981845 doi:10.1016/j.neuro.2012.08.014

43 Cheng G, Huang C, Deng H, Wang H. Diabetes as a risk factor for dementia and mild cognitive impairment: a meta-analysis of longitudinal studies. Intern Med J. 2012;42:484-91. Medline:22372522 doi:10.1111/j.1445-5994.2012.02758.x

44 Sahathevan R, Brodtmann A, Donnan GA. Dementia, stroke, and vascular risk factors; a review. Int J Stroke. 2012; 7:6173. Medline:22188853 doi:10.1111/j.1747-4949.2011.00731.x

45 Sharp SI, Aarsland D, Day S, Sonnesyn H, Alzheimer's Society Vascular Dementia Systematic Review G, Ballard C. Hypertension is a potential risk factor for vascular dementia: systematic review. Int J Geriatr Psychiatry. 2011;26:661-9. Medline:21495075 doi:10.1002/gps.2572 